\title{
Underestimated Survival of Campylobacter in Raw Milk Highlighted by Viability Real-Time PCR and Growth Recovery
}

\author{
Imke F. Wulsten ${ }^{1}$, Alibek Galeev ${ }^{2}$ and Kerstin Stingl ${ }^{1 *}$
}

${ }^{1}$ National Reference Laboratory for Campylobacter, Department of Biological Safety, German Federal Institute for Risk Assessment (BfR), Berlin, Germany, ${ }^{2}$ Institute of Medical Microbiology and Hospital Epidemiology, Hannover Medical School $(\mathrm{MHH})$, Hannover, Germany

Raw milk is a frequent vehicle for transmission of thermophilic Campylobacter, leading to reported outbreaks. Milk is a challenging food matrix for pathogen detection, due to its high protein and lipid content. Limited detection of Campylobacter colony-forming unit (CFU) in raw milk might underestimate the pathogen's infectious potential. We optimized a viability real-time PCR (qPCR) for application with raw milk. The procedure was robust against variations of milk lots and different Campylobacter strains. Various DNA-intercalating

\section{OPEN ACCESS}

Edited by: Javier Carballo, University of Vigo, Spain

Reviewed by: Marcello Trevisani, University of Bologna,

Italy

Anca loana Nicolau, Dunarea de Jos University, Romania

*Correspondence: Kerstin Stingl kerstin.stingl@bfr.bund.de

Specialty section: This article was submitted to

Food Microbiology, a section of the journal Frontiers in Microbiology

Received: 23 February 2020 Accepted: 04 May 2020 Published: 17 June 2020

Citation: Wulsten IF, Galeev A and Stingl K (2020) Underestimated Survival of

Campylobacter in Raw Milk Highlighted by Viability Real-Time PCR and Growth Recovery.

Front. Microbiol. 11:1107. doi: 10.3389/fmicb.2020.01107 dyes were evaluated for their ability to reduce the PCR signal of dead cells. Only propidium monoazide (PMA) and PMAxx qualified for diagnostic use. Different sedimentation properties of viable and dead Campylobacter jejuni and Campylobacter coli strains in 10-fold diluted milk enhanced viable/dead differentiation. The new method enabled to review survival of Campylobacter spp. in raw milk based on viable cells harboring an intact cell membrane. The data were compared to culturability according to ISO10272-2:2017. A difference of up to $4.5 \log _{10}$ between viable Campylobacter counts and CFU values became apparent. Relevance of viability qPCR values was corroborated by full recovery of CFU under extremely reduced oxygen concentration in the presence of hydrogen. Recovery of CFU was limited, however, upon prolonged exposure in raw milk. The data confirm that Campylobacter survival in raw milk can be largely underestimated when relying on CFU data only. We conclude that raw milk led to oxidative stress-induced growth arrest in thermophilic Campylobacter, which was reversible by reduction of the oxygen partial pressure in a time-limited way.

Keywords: propidium monoazide, viable but non-culturable, resuscitation, food safety, oxidative stress, real-time polymerase chain reaction

\section{INTRODUCTION}

In the European Union, campylobacteriosis is currently the most frequent bacterial food-borne disease, with 246,571 reported human cases in 2018 (EFSA, 2019). Acute symptoms include watery or bloody diarrhea, abdominal cramps, vomiting, and fever. Associated chronic complications involve reactive arthritis, inflammatory bowel disease, and neurological disorders such as Guillain-Barré syndrome (Keithlin et al., 2014). Rare fatal cases were reported in children less than 5 years of age and in elderly and immunocompromised patients (EFSA, 2019). 
Transmission of Campylobacter mainly occurs via contaminated food, by direct contact with colonized animals and also by untreated water (Kaakoush et al., 2015; MughiniGras et al., 2016; Rosner et al., 2017). Undercooked poultry meat and an insufficient kitchen hygiene related to raw meat handling are classical causes for the majority of sporadic cases. However, Campylobacter outbreaks are frequently reported upon consumption of raw milk (EFSA, 2018). Due to the repeal of the European milk quotas in 2015, farmers intensified the local sale of raw milk via milk-filling stations. In turn, consumer behavior changed in favor of an increased consumption of raw milk, neglecting prior heating recommendations. In Germany, 26\% of all reported foodassociated outbreaks with "high evidence" were caused by Campylobacter in 2018 (BVL, 2019). Most of them were caused by consumption of raw milk.

Cultural detection of Campylobacter in raw milk is difficult due to rapid decline of colony-forming unit (CFU) (Barrell, 1981; Doyle and Roman, 1982; Humphrey, 1986). Though considered fastidious in growth, Campylobacter are supposed to resist various environmental stresses. The genus has been suggested to outlast unfavorable environmental conditions in the viable but non-culturable (VBNC) state, putatively able to resuscitate and maintain its infective potential (Rollins and Colwell, 1986; Federighi et al., 1998; Baffone et al., 2006).

Real-time PCR (qPCR) offers a highly sensitive cultureindependent quantification method. It can be combined with a DNA intercalating agent, which enters dead cells, crosslinks to DNA, thereby impeding DNA amplification during PCR. This way, viable cells with an intact membrane can be differentiated from dead cells (Nocker et al., 2006; Krüger et al., 2014; Pacholewicz et al., 2019). It allows determining the highest possible residual risk present, while the minimal risk is indicated by CFU.

We established a culture-independent procedure that allows quantification of viable thermophilic Campylobacter in raw milk employing "viability qPCR." Applying this method, we investigated Campylobacter's survival in raw milk with intriguing results; a substantial survival of Campylobacter was observed by viability qPCR, while CFU dropped to non-detectable levels. To support our findings based on viability qPCR, recovery of CFU was demonstrated by lowering the partial pressure of oxygen beyond ISO standard recommendations (ISO 10272-2:2017).

\section{MATERIALS AND METHODS}

\section{Strains and Growth Conditions}

Campylobacter jejuni DSM 4688, Campylobacter coli DSM 4689, and Campylobacter sputorum DSM 5363 were derived from the DSMZ strain collection (DSMZ, Braunschweig, Germany). C. jejuni BfR-CA-13255, BfR-CA13290, BfR-CA-14727, BfR-CA-15123, and BfR-CA-15146 had been isolated from raw milk by the Federal State Laboratories in Germany.
Strains stored at $-80^{\circ} \mathrm{C}$ (MAST Group Ltd., Bootle, UK) were cultured on Columbia agar supplemented with $5 \%$ sheep blood (ColBA, Oxoid, Thermo Fisher Scientific Inc., Waltham, Massachusetts, USA) at $42^{\circ} \mathrm{C}$ under microaerobic conditions $\left(5 \% \mathrm{O}_{2}, 10 \% \mathrm{CO}_{2}\right.$, and $\left.85 \% \mathrm{~N}_{2}\right)$ in a microaerobic incubator (Binder $\mathrm{GmbH}$, Tuttlingen, Germany) for $24 \mathrm{~h}$. After subculture for $18 \pm 2 \mathrm{~h}$, cells were suspended in Brucella broth (BB, Beckon Dickinsen, Franklin Lakes, New Jersey, USA) at $\mathrm{OD}_{600}=0.2$, corresponding to $\sim 9 \log _{10}$ cell counts per $\mathrm{ml}$ (Krüger et al., 2014). The cells were 10-fold diluted to reach $8 \log _{10}$ cell counts per $\mathrm{ml}$ and kept on ice until further use (viable cells). The non-thermophilic $C$. sputorum was grown at $37^{\circ} \mathrm{C}$ on ColBA for initially $48 \mathrm{~h}$ starting from a $-80^{\circ} \mathrm{C}$ cryoculture. It was subcultured for $24 \mathrm{~h}$ and used for the production of a dead cell standard according to Pacholewicz et al. (2019).

Quantification by CFU was performed according to ISO 10272-2:2017 with BB as diluent and plating was performed in duplicate on mCCDA (Oxoid, Thermo Fisher Scientific., Waltham, Massachusetts, USA). The theoretical sensitivity was $1 \mathrm{CFU} / \mathrm{ml}$ milk. The standard incubation occurred for $48-72 \mathrm{~h}$ at $42^{\circ} \mathrm{C}$ using an atmosphere of $5 \% \mathrm{O}_{2}, 10 \% \mathrm{CO}_{2}$, and $85 \%$ $\mathrm{N}_{2}$ (a). Variation of atmospheric conditions was performed using incubators and gas replacement jars (Oxoid ${ }^{\mathrm{TM}}$ Anaerobia System, Thermo Fisher Scientific Inc., Waltham, Massachusetts, USA) filled with gas mixtures (Air Liquide, Paris, France). The detection limit for condition b-e. was $10 \mathrm{CFU} / \mathrm{ml}$ milk.

\section{Milk Lots and Spiking of the Samples}

To assess the effect of milk batch variations, different batches of raw tank milk were either received from the institute's own farming facility or collected from a regional milk producer. The fresh milk was kept at $4^{\circ} \mathrm{C}$ until processing, but not longer than $24 \mathrm{~h}$ after milking $(n=5)$. Frozen batches were stored at $-20^{\circ} \mathrm{C}$ for less than 10 days $(n=4)$ or more than 450 days $(n=2)$. For all other experiments, one of the long-term frozen milk batches was used in order to improve comparability of the results.

Milk samples were spiked with Campylobacter strains to reach an initial concentration of $6 \log _{10}$ cells/ml raw milk. The raw milk samples were kept in closed 50-ml tubes and incubated at $5 \pm 1{ }^{\circ} \mathrm{C}$ under normal atmospheric conditions. $\mathrm{pH}$ was stable and measured to be $6.7 \pm 0.1$ throughout the experiment. During a period of 6 days, samples were daily analyzed by $\mathrm{CFU}$ determination and viability $\mathrm{qPCR}$ analysis in parallel.

\section{Production of Dead and Transiently Inactive Viable Cells}

If not otherwise stated, C. jejuni dead cell standards served as sample process control (SPC) during each experiment. Cells were killed by incubating $8 \log _{10}$ cells in $100 \mu \mathrm{l}$ PBS supplemented with $5 \%$ hydrogen peroxide (Carl Roth $\mathrm{GmbH}$, Karlsruhe, Germany). After $1 \mathrm{~h}$ at room temperature, the cell suspension was diluted with $900 \mu \mathrm{l}$ PBS and the sample was then centrifuged at $16,000 \times g$ for $5 \mathrm{~min}$. The cell pellet 
was resuspended in $1 \mathrm{ml}$ PBS to obtain $8 \log _{10}$ inactivated cells per $\mathrm{ml}$, which were kept on ice until further use. In order to verify loss of CFU, $100 \mu \mathrm{l}$ of each dead cell standard was plated on ColbA.

For the production of transiently inactive cells, the protonophor cyanide-m-chlorophenylhydrazone (CCCP, SigmaAldrich, Steinheim, Germany) was applied. An amount of $8 \log _{10}$ cells in $1 \mathrm{ml}$ PBS was incubated with $100 \mu \mathrm{M}$ CCCP for $1 \mathrm{~h}$ on ice. We stained $6 \log _{10}$ CCCP-treated cells with intercalating dyes, while keeping $10 \mu \mathrm{M}$ CCCP during incubation. For CFU determination after recovery from CCCP stress, CCCP-treated cells were centrifuged at 16,000 $\times g$ for $5 \mathrm{~min}$, once washed with $1 \mathrm{ml} \mathrm{BB}$ and plated as described above.

\section{Differentiation Between Viable and Dead Cells}

From each raw milk sample, we took twice $1 \mathrm{ml}$; one of these two aliquots was processed without intercalating dye (total amount of cells) and the other was used with intercalating dye (only viable cells). Both aliquots were 10-fold diluted in $9 \mathrm{ml}$ of precooled $\mathrm{BB}$ and centrifuged at $8,000 \times g$ for $20 \mathrm{~min}$ at $4^{\circ} \mathrm{C}$ using $15 \mathrm{ml}$ centrifugation tubes. The supernatant ( $\mathrm{BB}$ with the major part of the milk components) was decanted and the remaining supernatant carefully withdrawn with a $1 \mathrm{ml}$ slim-shaft micropipette. The pellet was immediately suspended in $1 \mathrm{ml}$ PBS, transferred to a $1.5-\mathrm{ml}$ tube, and stored on ice until staining with the DNA intercalating dye.

During all experiments, propidium monoazide (PMA, Biotium Inc., Hayward, California, USA) was applied as DNA intercalating agent. When indicated, ethidium monoazide (EMA, Biotium Inc., Hayward, California, USA), PMAxx (Biotium Inc., Hayward, California, USA), or PEMAX (GenIUL, Terrassa, Spain) were used. Intercalating agents were applied at a final concentration of $50 \mu \mathrm{M}$. Stock solutions were stored in $20 \%$ dimethyl sulfoxide at $-20^{\circ} \mathrm{C}$. In order to guarantee an efficient reduction of the dead cell signal, control samples either contained dead C. jejuni cells (SPC) or dead C. sputorum cells (ISPC) at $6 \log _{10}$ cells $/ \mathrm{ml}$. The protocol was as previously described (Pacholewicz et al., 2019). In brief, samples were pre-incubated for $10 \mathrm{~min}$ at $30^{\circ} \mathrm{C}$ and $700 \mathrm{rpm}$ in a thermomixer, before addition of the DNA intercalating agent, shortly vortexed, and further incubated for $15 \mathrm{~min}$ at $30^{\circ} \mathrm{C}$ at $700 \mathrm{rpm}$ in the dark. Subsequently, samples were cross-linked for $15 \mathrm{~min}$ using the PhAST Blue photo-activation system (GenIUL, Terrassa, Spain) at $100 \%$ light intensity. Samples were centrifuged for $5 \mathrm{~min}$ at $16,000 \times g$, the supernatant was discarded, and the cell pellets were stored at $-20^{\circ} \mathrm{C}$ until DNA extraction.

\section{DNA Extraction and qPCR}

Genomic DNA was extracted using the GeneJet Genomic DNA Purification kit (Thermo Fisher Scientific Inc., Waltham, Massachusetts, USA) according to the manufacturer's instructions and extracted DNA was eluted in $100 \mu \mathrm{l}$. qPCR was carried out on the same day using $10 \mu \mathrm{l}$ of extracted DNA per reaction.
qPCR was performed targeting a fragment of the 16S rRNA gene of thermophilic Campylobacter or of C. sputorum (Pacholewicz et al., 2019). In short, the qPCR mastermix contained final concentrations of $1 \times$ Platinum Taq buffer, $2.5 \mathrm{mM} \mathrm{MgCl}_{2}, 0.2 \mathrm{mM}$ of each dNTP, $0.06 \times \mathrm{ROX}, 500 \mathrm{nM}$ of each Jos-F1 and Jos-R1 primer, $300 \mathrm{nM}$ of each IPC-ntb2-F and IPC-ntb2-R primer (HPLC-grade, Sigma-Aldrich, Steinheim, Germany), $100 \mathrm{nM}$ of each dark-quenched probe (IPC-ntb2P-TAMRA and Jos-P-FAM, TIB MOLBIOL, Berlin, Germany), $2 \mathrm{U}$ Platinum Taq DNA polymerase (Invitrogen, Thermo Fisher Scientific Inc., Waltham, Massachusetts, USA), and 25 copies of the IPC-ntb2 plasmid (Anderson et al., 2011) in a final qPCR reaction volume of $25 \mu \mathrm{l}$. qPCR was performed on a 7500 Real-Time PCR system (Applied Biosystems, Thermo Fisher Scientific, Waltham, Massachusetts, USA) using the 7500 Fast Software v2.3. The program started with $3 \mathrm{~min}$ at $95^{\circ} \mathrm{C}$ followed by 45 cycles of $15 \mathrm{~s}$ at $95^{\circ} \mathrm{C}, 1 \mathrm{~min}$ at $60^{\circ} \mathrm{C}$ and $30 \mathrm{~s}$ at $72^{\circ} \mathrm{C}$. For the quantitative detection of C. sputorum the mastermix was as above but contained instead of Jos-F1 and Jos-R1 the primer pair Csput-F and Csput-R. Likewise, the Jos-P probe was exchanged with the C. sputorum-specific probe Csput-P-Cy5 as detailed in Pacholewicz et al. (2019). The sequences of the primers and probes (quenched by the black berry quencher, BBQ) were as follows: Jos-F1 (5'-CCTGCTTAACACAAGTTGAGTAGG-3'), Jos-R1 (5' -TTCC TTAGGTACCGTCAGAATTC-3'), Jos-P (6FAM-TGTCATCCTC CACGCGGCGTTGCTGC-BBQ), IPC-ntb2-F (5'-ACCACAAT GCCAGAGTGACAAC-3'), IPC-ntb2-R (5'-TACCTGGTCTC CAGCTTTCAGTT-3'), IPC-ntb2-P (TAMRA-CACGCGCATG AAGTTAGGGGACCA-BBQ), Csput-F (5'-TGGGAAATGTAG CTCTTAATAATATATATC-3'), Csput-R (5' -CCTTACCAACTA GCTGATACAATATAG-3'), and Csput-P (Cy5-CCTCATCCCA TAGCGAAAGCTCTT-BBQ).

Each qPCR run contained genomic standards, comprising five decile serial dilutions ranging from 50,000 to 5 genomic copies per reaction in duplicate. The genomic standard was freshly reconstituted from dried stabilized DNA aliquots as described previously (Pacholewicz et al., 2019).

\section{Statistical Analysis}

Data were analyzed using GraphPad Prism v. 5.01 software. Statistical analysis was performed using the Mann-Whitney $U$-test. Graphs display the mean values $\pm \mathrm{SD}$, unless stated otherwise.

\section{RESULTS}

\section{Establishing Quantification of Viable Campylobacter in Raw Milk by qPCR}

We intended to answer the crucial food safety question whether the recovery of thermophilic Campylobacter from raw milk samples by CFU underestimates viable Campylobacter cells. We previously improved a culture-independent viability qPCR optimized for chicken rinses (Pacholewicz et al., 2019). As expected, direct quantification from undiluted raw milk samples was unsuitable because of two reasons - the bacteria could not be centrifuged in a quantitative manner probably 
due to high protein and lipid contents, and the opaque nature of raw milk rendered staining and proper crosslinking of DNA in dead bacteria inefficient.

Thus, we diluted raw milk samples 10 -fold in precooled $\mathrm{BB}$ in order to quantitatively harvest Campylobacter upon centrifugation and to reduce the amount of milk compounds putatively deteriorating the staining procedure (Figure 1). After resuspension of the bacterial pellet, various DNA intercalating dyes were tested. A proper method would lead to efficient elimination of the DNA amplification signal of dead cells. Meanwhile, it would most effectively amplify DNA of viable cells, even though these viable cells were transiently inactive in terms of growth. We wondered if the recently commercialized PMAxx and PEMAX agents had improved properties in the viable/dead differentiation protocol. In comparison with the known agents PMA and EMA, we examined their performance in the viability qPCR (Figure 2). For this purpose, C. jejuni DSM 4688 grown on ColBA for 18-20 $\mathrm{h}$ was resuspended in $\mathrm{BB}$ and used as viable untreated cells. Dead bacteria were produced by inactivation via oxidative stress as previously described (Krüger et al., 2014). Transiently inactivated cells were produced by treatment with $100 \mu \mathrm{M}$ of the protonophor CCCP, abolishing the proton-motif force of the bacterium. Subsequently, $6 \log _{10}$ per $\mathrm{ml}$ of these differently treated cells were stained with the various dyes and processed via $\mathrm{qPCR}$ and $\mathrm{CFU}$ determination (Figure 2).

Viable cells showed nearly identical CFU and live qPCR counts $\left(5.17 \pm 0.2 \log _{10}\right.$ live bacteria per $\mathrm{ml}$ and $5.13 \pm 0.25$ $\log _{10}$ CFU per $\mathrm{ml}$ qPCR counts in the presence of PMA; Figure 2, orange and gray bar). Around 10-fold more total genomic copies were detected via $\mathrm{qPCR}\left(6.02 \pm 0.08 \log _{10}\right.$ per $\mathrm{ml}$ without any DNA intercalating dye; Figure 2, blue bar). These results are in agreement with previous data, demonstrating that only around every tenth C. jejuni DSM 4688 precultured under similar conditions displayed CFU capability (Krüger et al., 2014). CCCP-treated cells nearly fully restored their ability to form CFU upon release of CCCP stress (4.89 $\pm 0.34 \log _{10} \mathrm{CFU} / \mathrm{ml}$; Figure 2, gray bar) and $\mathrm{qPCR}$ results with PMA very well-matched CFU determinations $\left(4.94 \pm 0.32 \log _{10} / \mathrm{ml}\right)$. In contrast, cells inactivated with $5 \%$ $\mathrm{H}_{2} \mathrm{O}_{2}$ (dead) were not able to form any CFU (Figure 2, gray bar). Likewise, all tested DNA intercalating agents reduced the detection of dead cells by $\geq 2.8 \log _{10} / \mathrm{ml}$ genomic copies. This confirmed their ability to efficiently reduce the signal of dead cells under the tested conditions.

As observed before (Krüger et al., 2014) and also suggested for other bacteria (Nocker et al., 2006; Codony et al., 2015), EMA was indicative of metabolic activity and was not passively excluded from viable cells. Consistently, EMA largely underestimated transiently inactivated C. jejuni $(2.35 \pm 0.31$ $\log _{10} / \mathrm{ml}$ and $3.84 \pm 0.44 \log _{10} / \mathrm{ml}$ genomic copies, respectively) and apparently entered viable bacteria. PMAxx led to slightly higher $\mathrm{qPCR}$ results than displayed by CFU, while PEMAX led to lower quantification of transiently inactivated (CCCPtreated) bacteria.

These observations indicate that PMA and PMAxx were passively excluded from intact bacteria. In contrast, PEMAX partially entered de-energized cells, but with less efficiency than EMA. Hence, we confirmed that PMA was the most suitable agent for viable/dead differentiation of $C$. jejuni cells.

\section{Variation of Milk Lots and Campylobacter Strains}

We scrutinized the viable/dead differentiating qPCR with regard to reproducible results upon matrix and strain variations. For this reason, different milk lots $(n=11$; Figure 3A) and different Campylobacter strains $(n=7$, including six C. jejuni and one C. coli; Figure 3B) were included in the experiments.

Viable cells of C. jejuni BfR-CA-13290 were reliably quantified in both PBS and raw milk using PMA or PMAxx, irrespective of various milk lots (Figure 3A). Likewise, different thermophilic Campylobacter strains could also be consistently quantified with only minor variations (Figure 3B). Interestingly, we observed

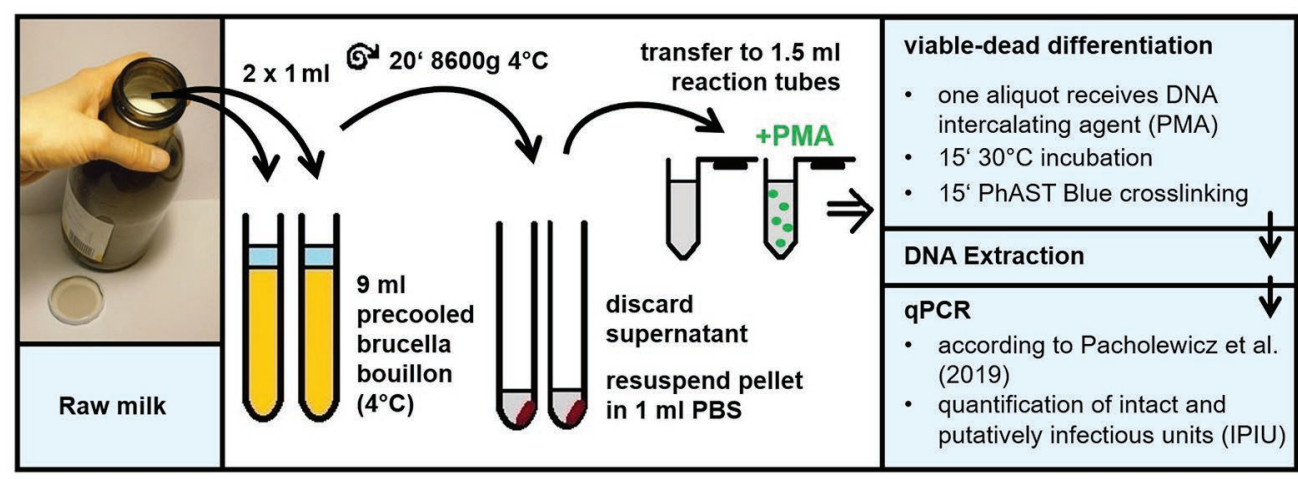

FIGURE 1 | Schematic overview of the culture-independent method for quantification of viable Campylobacter in raw milk. The method comprises the following steps. Raw milk is diluted 10-fold in precooled Brucella broth to enable quantitative bacterial centrifugation. After careful withdrawal of non-pelleted raw milk residues, the pellet is resuspended in $1 \mathrm{ml}$ PBS for viable/dead differentiation according to Krüger et al. (2014). Subsequently, the DNA intercalating agent is applied to block DNA of dead bacteria from PCR amplification. After DNA extraction qPCR is performed targeting the $16 \mathrm{~S}$ rRNA sequence in intact and putatively infectious units of thermophilic Campylobacter according to Pacholewicz et al. (2019). 


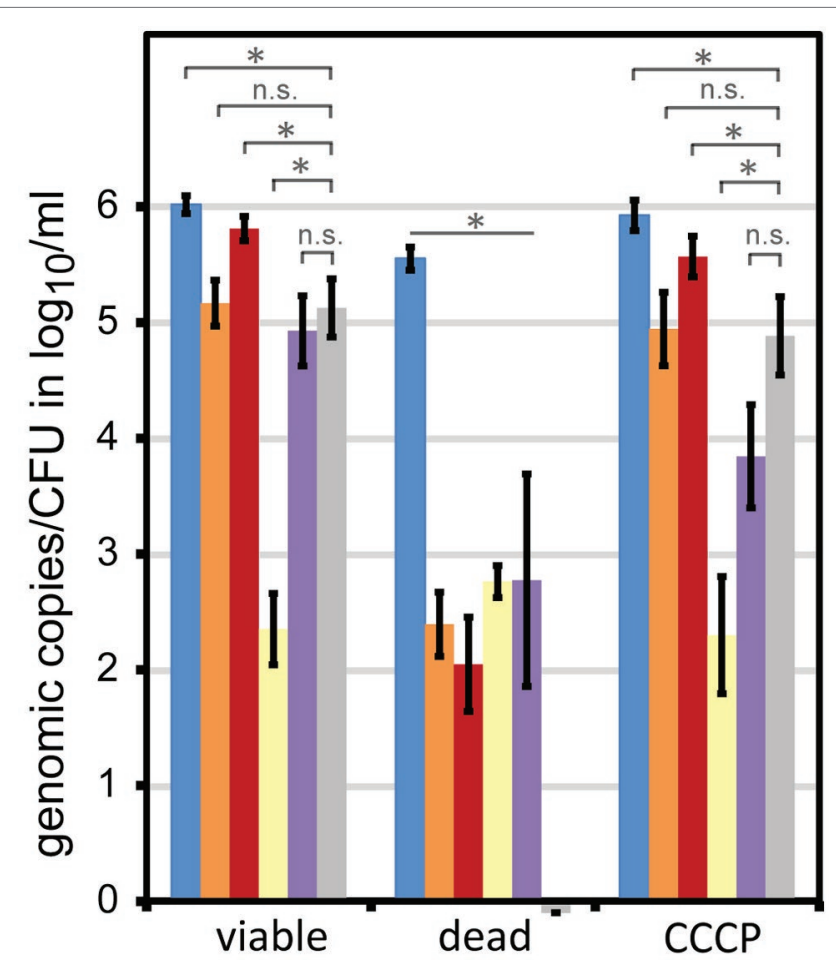

FIGURE 2 | Signal reduction in dead and transiently inactive Campylobacter by different DNA intercalating agents. C. jejuni DSM 4688 were grown on ColbA for 18-20 h (viable bacteria). The bacteria were either killed by $\mathrm{H}_{2} \mathrm{O}_{2}$ or transiently inactivated using the protonophore CCCP. Fifty $\mu \mathrm{M}$ of the respective DNA intercalating agent was applied to $6 \log _{10}$ bacteria per $\mathrm{ml}$ PBS. Columns display mean values \pm standard deviation of genomic copies (blue, without treatment; orange, propidium monoazide (PMA); red, PMAxx; yellow, EMA; purple, PEMAX) or CFU (gray bars); dataset includes five independent experiments; ${ }^{*} p<0.01$; n.s., non-significant (two-tailed MannWhitney U-test).

a partial loss $\left(\sim 2 \log _{10}\right)$ of dead C. jejuni by centrifugation, which was strain-dependent (Figures $\mathbf{3 A}$,B, dead, blue bars) and most pronounced for strain BfR-CA-13290. In contrast, viable cells were reproducibly retrieved independent of the strain tested. Hence, in combination with PMA or PMAxx treatment, viable/dead differentiation was even improved in raw milk compared to PBS. Dead C. sputorum cells, previously established as internal sample process control (ISPC) (Pacholewicz et al., 2019), were quantitatively retrieved from milk samples (Figure 3C), rendering this ISPC suitable for monitoring DNA loss for the reduction of the dead cell signal in raw milk.

\section{Survival of Campylobacter in Raw Milk at Refrigeration Temperatures}

With the new method at hand, we studied the survival of three Campylobacter strains in raw milk stored under aerobic conditions at $5 \pm 1^{\circ} \mathrm{C}$. Two reference strains (C. jejuni DSM 4688 and C. coli DSM 4689) and the outbreak-associated strain isolated from raw milk (C. jejuni BfR-CA-13290) were each spiked at an initial inoculum of $6 \log _{10} / \mathrm{ml}$. The milk samples were daily analyzed over a period of 6 days by viability qPCR and CFU determination (Figure 4).

As expected, CFU significantly decreased over time in a strain-dependent manner. CFU of C. coli DSM 4689 rapidly declined and the strain was uncultivatable within 3 days (Figure 4, dashed blue line). The CFU of C. jejuni BfR-CA13290 declined most slowly and the strain was undetectable after 6 days in most experiments (Figure 4, dashed green line). CFU loss kinetics of C. jejuni DSM 4688 was intermediate of $C$. coli and the C. jejuni outbreak strain (Figure 4, dashed red line).

In contrast, the amount of intact and putatively infectious units (IPIU) only marginally decreased by around $1 \log _{10} / \mathrm{ml}$ for the two C. jejuni strains and to a level of $\sim 4 \log _{10} / \mathrm{ml}$ for the $C$. coli strains during the first 2 days. Subsequently, IPIU remained on these levels throughout the whole experiment (Figure 4, solid lines). At the end of the experiment, we observed a large discrepancy between CFU and IPIU for all three strains, i.e., absence of CFU and still $\log 4-4.5$ IPIU detected by viability $\mathrm{qPCR}$.

\section{Recovery of CFU at Altered Culture Conditions}

We questioned whether the observed prolonged survival in raw milk as assessed by viability $\mathrm{qPCR}$ reflected a real existent food safety issue, i.e., that bacteria were indeed viable. For this purpose, we intended to identify parameters critical for Campylobacter growth after exposure to raw milk.

We selected consecutive time points at which several growth conditions were tested in parallel. Campylobacter as a microaerobic organism is susceptible to oxidative stress outside its multiplication site. Thus, we tested whether altered temperature and atmospheric conditions can revert its capability to form CFU in vitro. We tested four alternative conditions (Figure 5B) in parallel to the standard condition of $42^{\circ} \mathrm{C}$ and an atmosphere of $5 \% \mathrm{O}_{2}, 10 \% \mathrm{CO}_{2}$, and rest $\mathrm{N}_{2}$ (a). Condition b only differed by reduction of the temperature to $37^{\circ} \mathrm{C}$. Furthermore, we additionally changed the concentrations of $\mathrm{O}_{2}$ ( $1 \%$ for $\mathrm{c}$ and $\mathrm{d}, 6 \%$ for e), $\mathrm{CO}_{2}$ (7\% for e), and eventually added hydrogen $(3.5 \%$ for $\mathrm{d}$ and e). The incubation time for optimal colony counting varied between the conditions. In the presence of $5-6 \%$ oxygen ( $a, b$, and e), growth of Campylobacter led to well visible colonies after 2-3 days. It was confirmed that a prolonged incubation time did not lead to additional CFU. In contrast, at reduced oxygen levels ( $c$ and $d$ ), colonies grew slower, so that CFU were optimally counted after 4-5 days.

Alteration of atmospheric conditions significantly increased CFU in all strains tested in a time point- and strain-dependent manner (Figure 5, conditions c-e). Reduced temperature eventually increased CFU recovery at early time points in C. jejuni strains, but the extent of this increase was less than $1 \log _{10} / \mathrm{ml}$ (Figure 5, condition b). The condition, in which hydrogen was present and oxygen was reduced to $1 \%$, resulted in maximal CFU detected for all strains (Figure 5, condition d). 

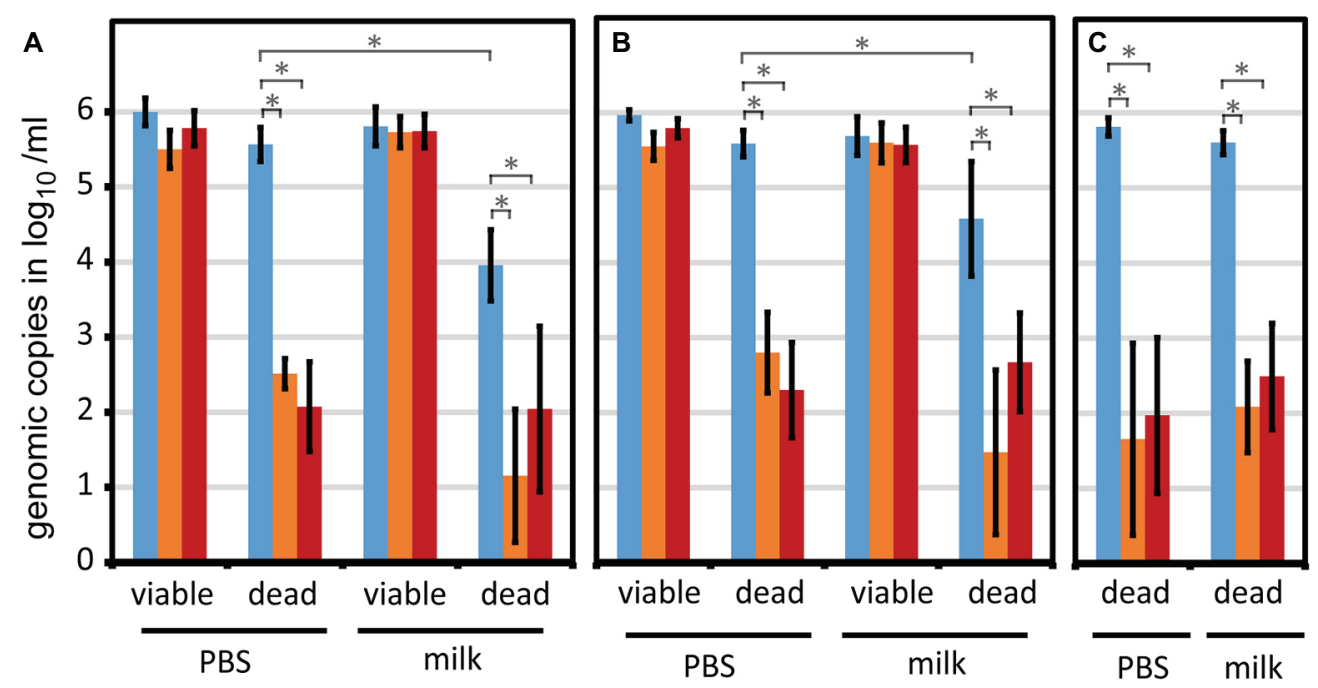

FIGURE 3 | The viability qPCR method is robust against different milk lots and strains variations. Viable or $\mathrm{H}_{2} \mathrm{O}_{2}$-inactivated Campylobacter were spiked at $6 \log _{10} / \mathrm{ml}$ into PBS or raw milk. Genomic counts were determined by qPCR upon differentiation of viable and dead cells using PMA or PMAxx. (A) Eleven different lots of raw milk (either fresh or after $-20^{\circ} \mathrm{C}$ storage) were tested using the strain C. jejuni BfR-CA-13290; (B) Seven different Campylobacter strains (two reference strains and five field strains) were analyzed using one milk lot. (C) Five experiments were performed with $\mathrm{H}_{2} \mathrm{O}_{2}$-inactivated C. sputorum DSM 5363 as potential internal sample process control (Pacholewicz et al., 2019). Absence of rest signal from dead cells was defined as $-0.1 \log _{10} / \mathrm{ml}$ for enabling calculations. Blue, no treatment; orange, PMA; red, PMAxx. Columns display mean values \pm standard deviation. ${ }^{*} p<0.01$; n.s., non-significant (two-tailed Mann-Whitney U-test).

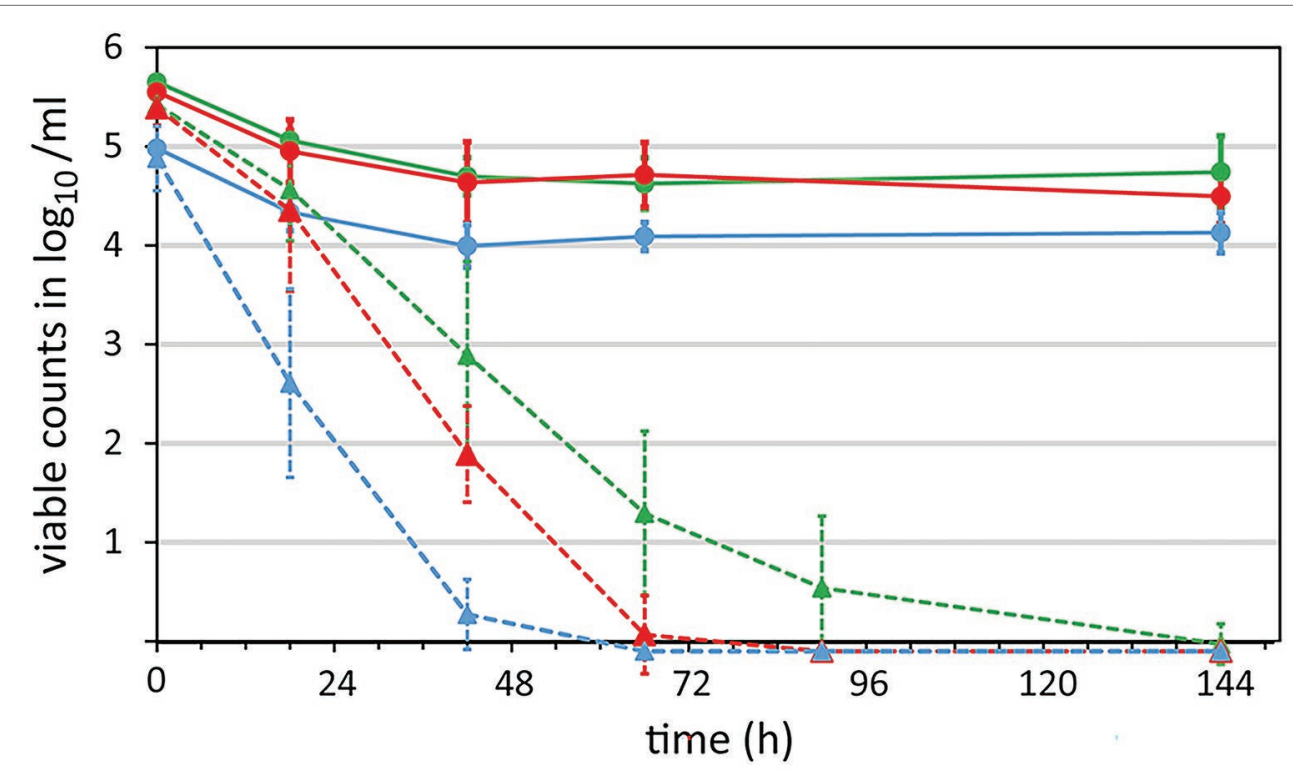

FIGURE 4 | Survival of Campylobacter in raw milk. Three Campylobacter strains were spiked at $6 \log _{10} / \mathrm{ml}$ bacterial counts in raw milk and stored aerobically at refrigeration temperatures. Samples were taken over time to quantify the survival by viability qPCR (solid lines) and CFU according to ISO 10272-2:2017 (dotted lines). Blue, C. coli DSM 4689; red, C. jejuni DSM 4688; green, C. jejuni BfR-CA-13290. Absence of CFU or genomic copies was defined as -0.1 log $10 / \mathrm{ml}$ for enabling calculations. Mean values \pm standard deviations are shown from at least five independent experiments.

In comparison with the original condition (Figure 5, condition a) reduction of oxygen and addition of hydrogen maximally increased CFU by $\log 4.5 \log _{10} / \mathrm{ml}$ in C. jejuni BfR-CA13290 after 6 days of exposure in milk. Hence, the gap between the initial CFU read-out under standard conditions and the viability qPCR read-out of IPIU was completely bridged (Figure 4). In the other two strains, CFU increased at most by 2.5 (at T2, $66 \mathrm{~h}$ ) and $3 \log _{10}$ per $\mathrm{ml}(\mathrm{T} 1,42 \mathrm{~h}$ ) for C. jejuni DSM 4688 and C. coli DSM 4689, respectively. However, stimulating CFU recovery under reduced oxygen conditions in the presence of hydrogen was dependent on the time point of investigation, since the magnitude of CFU 


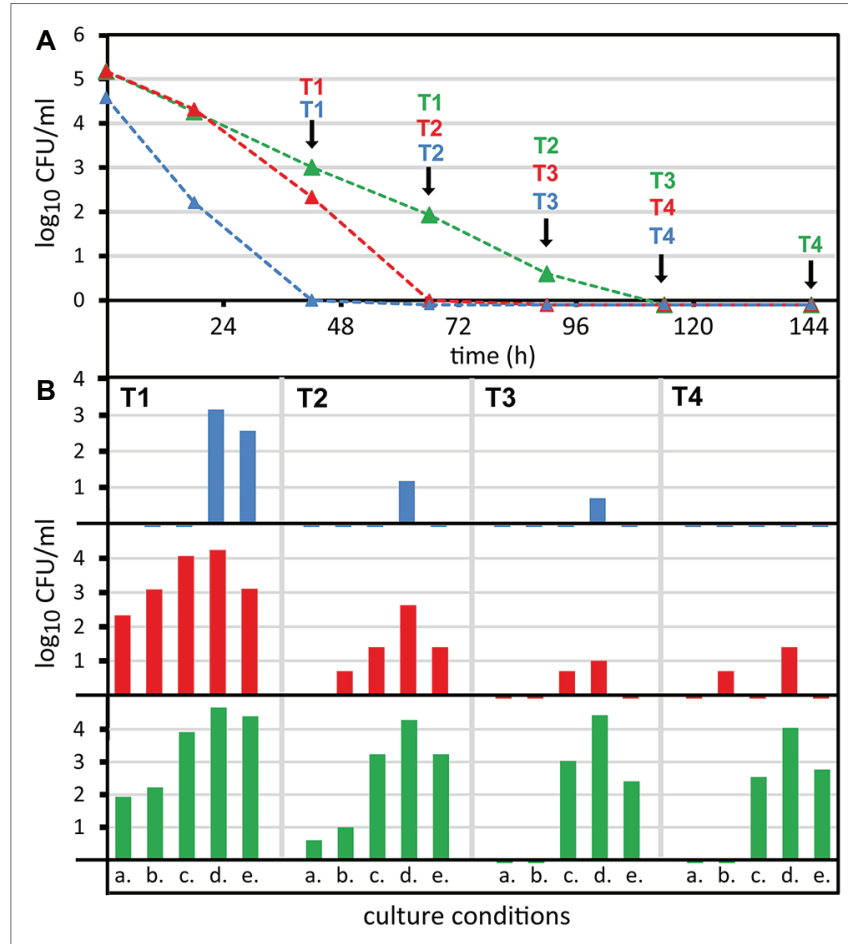

FIGURE 5 | Recovery of non-culturable Campylobacter from raw milk by reduction of oxygen partial pressure. Campylobacter were spiked at $6 \log _{10} /$ $\mathrm{ml}$ bacterial counts into raw milk and stored refrigerated. (A) Colony-forming unit (CFU) was determined under standard conditions $\left(5 \% \mathrm{O}_{2}, 10 \% \mathrm{CO}_{2}\right.$, rest $\mathrm{N}_{2}$ at $42^{\circ} \mathrm{C}$, condition a.). (B) At selected time points (T1-T4) enumeration was performed under four alternative microaerobic culture conditions. Alternative culture conditions at $37^{\circ} \mathrm{C}$ and with $\mathrm{N}_{2}$ as background gas: b. $5 \%$ $\mathrm{O}_{2}, 10 \% \mathrm{CO}_{2}$; c. $1 \% \mathrm{O}_{2}, 10 \% \mathrm{CO}_{2}$; d. $3.5 \% \mathrm{H}_{2}, 1 \% \mathrm{O}_{2}, 10 \% \mathrm{CO}_{2}$; e. $3.5 \%$ $\mathrm{H}_{2}, 6 \% \mathrm{O}_{2}, 7 \% \mathrm{CO}_{2}$. Mean values of one representative experiment are shown for three strains (blue, Campylobacter coli DSM 4689; red, Campylobacter jejuni DSM 4688; green, C. jejuni BfR-CA-13290). Viability qPCR initially detected 5.0-5.6 $\log _{10} / \mathrm{ml}$ viable counts and $4.4-4.72 \log _{10} / \mathrm{ml}$ after $144 \mathrm{~h}$ of exposure in raw milk for the three strains.

increase diminished with exposure time of Campylobacter in raw milk at $5 \pm 1{ }^{\circ} \mathrm{C}$.

Our experiments demonstrated, for the first time, that the measured number of IPIU determined by viability qPCR are indeed relevant, since we found distinct conditions under which CFU could completely be restored.

\section{DISCUSSION}

Raw milk is an important vehicle for Campylobacter transmission and frequently involved in reported outbreaks. The raw milk matrix is challenging from the food safety perspective, since Campylobacter are difficult to be detected due to rapid decline in CFU. Current alternative methods target detection of Campylobacter after enrichment of raw milk in broth (Razzuoli et al., 2018) or by using in-line milk filters with higher pathogen contamination (FSAI, 2015; Artursson et al., 2018). To our knowledge, no culture-independent direct quantification method is so far available for raw milk. In the present study, we established a viability qPCR method, which allows quantifying IPIU of Campylobacter in raw milk. Furthermore, survival of Campylobacter spp. in raw milk was reassessed by qPCR and CFU. The proposed method was found to be robust against different milk batches and also suitable for different $C$. jejuni strains, the major species responsible for campylobacteriosis (EFSA, 2019).

While the standardized plate count approach has a quantitative sensitivity of $10 \mathrm{CFU} / \mathrm{ml}$ according to ISO 7218:2014, our qPCR-based method is 10-fold less sensitive due to limits of PMA staining and DNA extraction. However, we showed that qPCR can detect $4.5 \log _{10} / \mathrm{ml}$ more viable C. jejuni in comparison to $\mathrm{CFU}$ enumeration under standard culture conditions (Figure 5). The results indicated an initial $1 \log _{10} / \mathrm{ml}$ reduction in viable cells of the outbreak-associated C. jejuni strain within the first $42 \mathrm{~h}$ in raw milk. Notably, the remaining population appeared to cease their capacity to form colonies under normal growth conditions. Nevertheless, genomic DNA was protected by an intact cell membrane, which was inaccessible by PMA. In order to prove that $\mathrm{qPCR}$ results of viable bacteria are relevant for food safety, we bridged the gap between CFU and viability $\mathrm{qPCR}$.

According to the standard protocols for enhanced enrichment of stressed Campylobacter, growth temperature is decreased for several hours to $37^{\circ} \mathrm{C}$ (ISO 10272-1:2017) based on observations of improved CFU recovery after cold stress (Humphrey, 1986). However, the effect of temperature reduction from $42^{\circ} \mathrm{C}$ to $37^{\circ} \mathrm{C}$ on increased C. jejuni $\mathrm{CFU}$ levels after raw milk exposure was negligible (Figure 5B, condition b).

Importantly, despite of decreasing CFU under standard conditions, an extremely low oxygen partial pressure $\left(1 \% \mathrm{O}_{2}\right.$ in combination with $3.5 \% \mathrm{H}_{2}$ ) reactivated Campylobacter to quantitatively grow on mCCDA (Figure 5B). These results contradict the traditional interpretation that reduced $\mathrm{CFU}$ necessarily reflect reduced viability of the pathogenic bacterium and demonstrate, for the first time, that "viability qPCR" detected IPIU indeed mirror viable cells.

Interestingly, addition of hydrogen (Figure 5, condition c) or lowering oxygen concentration (Figure 5, condition e) both stimulated growth of Campylobacter. The combination of hydrogen and low oxygen concentration had a cumulative effect on CFU recovery (Figure 5, condition d). Since hydrogen functions as electron donor of the respiratory chain (van der Stel et al., 2017), it may also enhance respiratory activity and further consumption of oxygen within the cell. Putatively, these results hint to the presence of a yet unknown oxidative stress response sensor, which regulates replication and/or division in thermophilic Campylobacter. It was shown previously that C. jejuni adapts to various microaerobic atmospheres by significantly changing transcription of specific genes, e.g., involved in detoxification (John et al., 2011). Furthermore, C. jejuni showed prolonged survival under atmospheric conditions in the presence of the oxygen-consuming bacterium Pseudomonas spp. (Hilbert et al., 2010).

Nevertheless, the potential to recover CFU by drastic decrease of oxygen was diminished with time of exposure in milk, suggesting further yet unknown signals/regulators for entry and exit of the non-culturable state of Campylobacter. 


\section{CONCLUSION}

The presented work illustrates the underestimation of Campylobacter survival by standard plate count conditions in raw milk and calls for complementary culture-independent quantification of viable cells to improve risk assessment. Incubation under lowered oxygen tension in the presence of hydrogen was demonstrated to improve Campylobacter detection from raw milk in a time-limited way. Consequently, risk assessment of contaminated foods based on CFU might lead to an underestimation of the actual risk to human health. Future studies will decipher further parameters for reactivating Campylobacter culturability upon stress exposure in food matrices and in the environment. They will reveal so far unknown transmission routes as well as persistence niches of the versatile food-borne pathogen.

\section{DATA AVAILABILITY STATEMENT}

All datasets generated for this study are included in the article.

\section{REFERENCES}

Anderson, A., Pietsch, K., Zucker, R., Mayr, A., Müller-Hohe, E., Messelhäusser, U., et al. (2011). Validation of a duplex real-time PCR for the detection of Salmonella spp. in different food products. Food Anal. Methods 4, 259-267. doi: 10.1007/s12161-010-9142-8

Artursson, K., Schelin, J., Thisted Lambertz, S., Hansson, I., and Olsson Engvall, E. (2018). Foodborne pathogens in unpasteurized milk in Sweden. Int. J. Food Microbiol. 284, 120-127. doi: 10.1016/j.ijfoodmicro.2018.05.015

Baffone, W., Casaroli, A., Citterio, B., Pierfelici, L., Campana, R., Vittoria, E., et al. (2006). Campylobacter jejuni loss of culturability in aqueous microcosms and ability to resuscitate in a mouse model. Int. J. Food Microbiol. 107, 83-91. doi: 10.1016/j.ijfoodmicro.2005.08.015

Barrell, R. A. (1981). The survival of Campylobacter coli/jejuni in unpasteurised milk. J. Infect. 3, 348-352. doi: 10.1016/S0163-4453(81)91939-3

BVL (2019). Common national report of BVL and RKI on food-borne infections in Germany in 2018; in German (Gemeinsamer nationaler Bericht des BVL und RKI zu lebensmittelbedingten Krankheitsausbrüchen in Deutschland 2018).

Codony, F., Agusti, G., and Allue-Guardia, A. (2015). Cell membrane integrity and distinguishing between metabolically active and inactive cells as a means of improving viability PCR. Mol. Cell. Probes 29, 190-192. doi: 10.1016/j. mcp.2015.03.003

Doyle, M. P., and Roman, D. J. (1982). Prevalence and survival of Campylobacter jejuni in unpasteurized milk. Appl. Environ. Microbiol. 44, 1154-1158. doi: 10.1128/AEM.44.5.1154-1158.1982

EFSA (2018). The European Union summary report on trends and sources of zoonoses, zoonotic agents and food-borne outbreaks in 2017. EFSA J. 16:e05500. doi: 10.2903/j.efsa.2018.5500

EFSA (2019). The European Union One Health 2018 Zoonoses Report. EFSA J. 17:e05926. doi: 10.2903/j.efsa.2019.5926

Federighi, M., Tholozan, J. L., Cappelier, J. M., Tissier, J. P., and Jouve, J. L. (1998). Evidence of non-coccoid viable but non-culturable Campylobacter jejuni cells in microcosm water by direct viable count, CTC-DAPI double staining, and scanning electron microscopy. Food Microbiol. 15, 539-550. doi: $10.1006 /$ fmic.1998.0181

FSAI (2015). Raw milk and raw milk filters; Microbial Surveillance Programme (12NS2). Monitoring and surveillance series. Microbiology, Food Safety Authority of Ireland.

Hilbert, F., Scherwitzel, M., Paulsen, P., and Szostak, M. P. (2010). Survival of Campylobacter jejuni under conditions of atmospheric oxygen tension with

\section{AUTHOR CONTRIBUTIONS}

IW performed experiments, analyzed data and co-wrote the manuscript. AG performed experiments. KS designed the study, analyzed data and co-wrote the manuscript.

\section{FUNDING}

This work was funded by SFB 1322-580 of German Federal Institute for Risk Assessment (BfR). IW was financed by the research project EsRAM (No. 2817701614) of the German Federal Ministry of Food and Agriculture (BMEL). AG received an Erasmus grant during his studies at BfR.

\section{ACKNOWLEDGMENTS}

We thank Mrs. Lochotzke from the farm facility of BfR for the milk batches and our colleagues of the Federal State Laboratories in Germany for isolation of C. jejuni from raw milk.

the support of Pseudomonas spp. Appl. Environ. Microbiol. 76, 5911-5917. doi: 10.1128/AEM.01532-10

Humphrey, T. J. (1986). Techniques for the optimum recovery of cold injured Campylobacter jejuni from milk or water. J. Appl. Bacteriol. 61, 125-132. doi: 10.1111/j.1365-2672.1986.tb04265.x

ISO 7218:2014. Microbiology of food and animal feeding stuffs-general requirements and guidance for microbiological examinations.

ISO 10272-1:2017. Microbiology of the food chain-horizontal method for detection and enumeration of Campylobacter spp.-part 1: detection method.

ISO 10272-2:2017. Microbiology of the food chain-horizontal method for detection and enumeration of Campylobacter spp.-part 2: colony-count technique.

John, A., Connerton, P. L., Cummings, N., and Connerton, I. F. (2011). Profound differences in the transcriptome of Campylobacter jejuni grown in two different, widely used, microaerobic atmospheres. Res. Microbiol. 162, 410-418. doi: 10.1016/j.resmic.2011.02.004

Kaakoush, N. O., Castano-Rodriguez, N., Mitchell, H. M., and Man, S. M. (2015). Global epidemiology of Campylobacter infection. Clin. Microbiol. Rev. 28, 687-720. doi: 10.1128/CMR.00006-15

Keithlin, J., Sargeant, J., Thomas, M. K., and Fazil, A. (2014). Systematic review and meta-analysis of the proportion of Campylobacter cases that develop chronic sequelae. BMC Public Health 14:1203. doi: 10.1186/1471-2458-14-1203

Krüger, N. J., Buhler, C., Iwobi, A. N., Huber, I., Ellerbroek, L., Appel, B., et al. (2014). "Limits of control"-crucial parameters for a reliable quantification of viable Campylobacter by real-time PCR. PLoS One 9:e88108. doi: 10.1371/ journal.pone.0088108

Mughini-Gras, L., Penny, C., Ragimbeau, C., Schets, F. M., Blaak, H., Duim, B., et al. (2016). Quantifying potential sources of surface water contamination with Campylobacter jejuni and Campylobacter coli. Water Res. 101, 36-45. doi: 10.1016/j.watres.2016.05.069

Nocker, A., Cheung, C. Y., and Camper, A. K. (2006). Comparison of propidium monoazide with ethidium monoazide for differentiation of live vs. dead bacteria by selective removal of DNA from dead cells. J. Microbiol. Methods 67, 310-320. doi: 10.1016/j.mimet.2006.04.015

Pacholewicz, E., Buhler, C., Wulsten, I. F., Kraushaar, B., Luu, H. Q., Iwobi, A. N., et al. (2019). Internal sample process control improves cultivation-independent quantification of thermotolerant Campylobacter. Food Microbiol. 78, 53-61. doi: 10.1016/j.fm.2018.09.017

Razzuoli, E., Vencia, W., Fedele, V., Mignone, G., Lazzara, F., Rubini, D., et al. (2018). Evaluation and validation of an alternative method to detect Campylobacter spp. in dairy products. Ital. J. Food Saf. 7:7180. doi: 10.4081/ ijfs.2018.7180 
Rollins, D. M., and Colwell, R. R. (1986). Viable but nonculturable stage of Campylobacter jejuni and its role in survival in the natural aquatic environment. Appl. Environ. Microbiol. 52, 531-538. doi: 10.1128/AEM.52.3.531-538.1986 Rosner, B. M., Schielke, A., Didelot, X., Kops, F., Breidenbach, J., Willrich, N., et al. (2017). A combined case-control and molecular source attribution study of human Campylobacter infections in Germany, 2011-2014. Sci. Rep. 7:5139. doi: 10.1038/s41598-017-05227-x

Van Der Stel, A. X., Boogerd, F. C., Huynh, S., Parker, C. T., Van Dijk, L., Van Putten, J. P. M., et al. (2017). Generation of the membrane potential and its impact on the motility, ATP production and growth in Campylobacter jejuni. Mol. Microbiol. 105, 637-651. doi: 10.1111/mmi.13723
Conflict of Interest: The authors declare that the research was conducted in the absence of any commercial or financial relationships that could be construed as a potential conflict of interest.

Copyright (C) 2020 Wulsten, Galeev and Stingl. This is an open-access article distributed under the terms of the Creative Commons Attribution License (CC $B Y)$. The use, distribution or reproduction in other forums is permitted, provided the original author(s) and the copyright owner(s) are credited and that the original publication in this journal is cited, in accordance with accepted academic practice. No use, distribution or reproduction is permitted which does not comply with these terms. 